\title{
Population Attributable Fraction of Smoking and Metabolic Syndrome on Cardiovascular Disease Mortality in Japan: a 15-Year Follow Up of NIPPON DATA90
}

\author{
Naoyuki Takashima*1, Katsuyuki Miura1, Atsushi Hozawa1,2, Aya Kadota1, Tomonori Okamura³, Yasuyuki Nakamura4, \\ Takehito Hayakawa5, Nagako Okuda1, Akira Fujiyoshi', Shin-ya Nagasawa1, Takashi Kadowaki', Yoshitaka Murakami1, \\ Yoshikuni Kita1, Akira Okayama6, Hirotsugu Ueshima' for for the NIPPON DATA 90 Research group
}

\begin{abstract}
Background: Smoking and metabolic syndrome are known to be related to cardiovascular diseases (CVD) risk. In Asian countries, prevalence of obesity has increased and smoking rate in men is still high. We investigated the attribution of the combination of smoking and metabolic syndrome (or obesity) to excess CVD deaths in Japan.

Methods: A cohort of nationwide representative Japanese samples, a total of 6650 men and women aged 30-70 at baseline without history of CVD was followed for 15 years. Multivariate-adjusted hazard ratio for CVD death according to the combination of smoking status and metabolic syndrome (or obesity) was calculated using Cox proportional hazard model. Population attributable fraction (PAF) of CVD deaths was calculated using the hazard ratios.

Results: During the follow-up period, 87 men and 61 women died due to CVD. The PAF component of CVD deaths in non-obese smokers was $36.8 \%$ in men and $11.3 \%$ in women, which were higher than those in obese smokers $(9.1 \%$ in men and $5.2 \%$ in women). The PAF component of CVD deaths in smokers without metabolic syndrome was $40.9 \%$ in men and $11.9 \%$ in women, which were also higher than those in smokers with metabolic syndrome $(7.1 \%$ in men and $3.9 \%$ in women).

Conclusion: Our results indicated that a large proportion of excess CVD deaths was observed in smokers without metabolic syndrome or obesity, especially in men. These findings suggest that intervention targeting on smokers, irrespective of the presence of metabolic syndrome, is still important for the prevention of CVD in Asian countries.
\end{abstract}

\section{Background}

Obesity and clustering of its related factors, now called as metabolic syndrome, have been widely reported as important risk factors for cardiovascular diseases (CVD) [1-6], and, also in Asian countries including Japan, obesity has emerged as a new health problem [5]. The National Health and Nutrition Survey in Japan in 2005 showed that $22.4 \%$ of adult men and $10.8 \%$ of adult women were diagnosed as having metabolic syndrome [7]. Therefore, it is expected that metabolic syndrome or

* Correspondence: takasima@belle.shiga-med.ac.jp

1 Department of Health Science, Shiga University of Medical Science, Seta Tsukinowa-cho, Otsu, Shiga 520-2192, Japan

Full list of author information is available at the end of the article obesity would contribute to a large part of excess CVD events in Japan.

On the other hand, cigarette smoking is an established risk factor for CVD [8-12] and one of the biggest health problems in Asian countries including Japan $[9,12,13]$. In Asian countries, smoking rate in men is still high at 40 to 50\% [14]. In Japan, smoking rate in 2005 was also high at $39.3 \%$ in men [15]. Therefore, smoking has largely contributed to increase CVD events in Asia, and it was reported that up to $30 \%$ of cardiovascular deaths was attributed by smoking in Asia Pacific region [16].

However, there have been few reports on the attribution of the combination of smoking status and metabolic syndrome (or obesity) to CVD deaths in Asian countries. 
Several previous studies also reported that CVD risk was high in both smokers and non-smokers with clustering of metabolic risk factors [17]. Therefore, it is important to elucidate the attribution of obesity, metabolic syndrome, and smoking to CVD mortality in Asia, where obesity is still less common compared with Western countries.

The purpose of this report is to examine excess CVD deaths and population attributable fractions on CVD deaths by the combination of smoking and metabolic syndrome (or obesity) in a 15-year cohort study of randomly selected representative Japanese samples from the National Survey on Circulatory Disorders of Japan.

\section{Methods}

\section{Participants and follow-up}

Cohort studies of the National Survey on Circulatory Disorders of Japan comprise the National Integrated Project for Prospective Observation of Non-communicable Disease and Its Trends in the Aged (NIPPON DATA). Baseline surveys for the cohort of this report were performed in 1990 (NIPPON DATA90) [18,19]. We analyzed the 15year follow-up data of NIPPON DATA90 in this report.

A total of 8383 men and women aged $\geq 30$ years from 300 randomly selected districts were participated in the survey in 1990. The baseline surveys were carried out at local public health centers. The participation rate in the baseline survey was $76.5 \%$. The present study was for 7329 participants aged 30 to 70 years at baseline. From these participants, we excluded 379 participants who had a history of coronary heart disease or stroke $(n=249)$ or who had missing information in the baseline survey $(\mathrm{n}=$ 130). Thus, 6650 participants $(2752$ men and 3898 women) were eligible for the analyses.

NIPPON DATA90 has completed follow-up surveys until 2005. We used the National Vital Statistics data to indentify the cause of death. The underlying causes of death in the National Vital Statistics were coded according to the $9^{\text {th }}$ International Classification of Disease (ICD9) until the end of 1994 and according to the $10^{\text {th }}$ International Classification of Disease (ICD-10) from 1995. Deaths from any CVD were identified by ICD-9 codes (393-459) and ICD-10 codes (I00-I99). The details of the classification are described elsewhere [18,19]. The Institutional Review Board of Shiga University of Medical Science (NO.12-18, 2000) approved the study.

\section{Biochemical and physical examinations}

Public health nurses obtained data including smoking habit, as well as current health status and medical history. Public health nurses asked all participants about current smoking status (current smoking, past smoking and never-smoking), the number of cigarettes per day and the duration of smoking. Smoking habit was categorized into non-smoker, past smoker and current smoker. Drinking habit was categorized into non-drinker, past drinker, occasional drinker and daily drinker. Body mass index was calculated as weight divided by height squared $(\mathrm{kg} /$ $\mathrm{m}^{2}$ ).

Non-fasting blood samples were obtained at the baseline survey. The serum was separated and centrifuged soon after blood coagulation. Plasma samples were collected in siliconized tubes containing sodium fluoride and shipped to one laboratory (SRL, Tokyo, Japan) for blood measurements. Plasma glucose was measured enzymatically. Serum triglycerides and total cholesterol were also measured enzymatically, and high density lipoprotein (HDL) cholesterol was measured after heparincalcium precipitation [20].

We defined metabolic risk factors using the Japanese criteria of the metabolic syndrome [21,22] as follow: obesity as body mass index $\geq 25 \mathrm{~kg} / \mathrm{m}^{2}$; high blood pressure: $\mathrm{BP} \geq 130 / 85 \mathrm{~mm} \mathrm{Hg}$ or on treatment for hypertension; high blood glucose: serum glucose $\geq 110 \mathrm{mg} / \mathrm{dl}$ or on treatment for diabetes; dyslipidemia: serum triglyceride $\geq$ $150 \mathrm{mg} / \mathrm{dl}$, HDL cholesterol $<40 \mathrm{mg} / \mathrm{dl}$ or on treatment for dyslipidemia. We defined the metabolic syndrome as having obesity (defined as body mass index $\geq 25 \mathrm{~kg} / \mathrm{m}^{2}$ ) and two or more other metabolic risk factors; the definition was modified from the Japanese criteria [22] where the presence of obesity is essential. We defined metabolic risk factors clustering as having two or more metabolic risk factors.

\section{Statistical analysis}

Multivariate-adjusted hazard ratios (HR) of all CVD deaths for each component of metabolic risk factors including BMI, systolic BP (SBP), triglyceride, glucose, HDL cholesterol were calculated using Cox proportional hazards models. Multivariate-adjusted HR for all CVD deaths according to metabolic risk factors and smoking categories were calculated using Cox proportional hazards models adjusted for age and drinking. Non-smokers without metabolic syndrome or obesity were set as the reference group.

Population attributable fractions (PAF) for CVD deaths due to the combination of smoking and metabolic syndrome (or obesity) were calculated based on hazard ratios assessed by proportional hazards models [23,24]. PAF was estimated as $p d \times(\mathrm{HR}-1) / \mathrm{HR}$ where $p d$ is the proportion of death cases arising from the each categories. All analyses were performed by SAS 9.1 (Statistical Analysis System, Cary, NC).

\section{Results}

Baseline characteristics are shown in Table 1. Mean age at baseline was 49.9 years in men and 49.0 years in women. Mean body mass index was $23.1 \mathrm{~kg} / \mathrm{m}^{2}$ in men and 22.9 $\mathrm{kg} / \mathrm{m}^{2}$ in women. Smoking rate was $58.0 \%$ in men and 
Table 1: Baseline characteristics of study population. NIPPON DATA90, men and women aged 30 to 70 years in 1990.

\begin{tabular}{|c|c|c|c|c|}
\hline & \multicolumn{2}{|c|}{ Men } & \multicolumn{2}{|c|}{ Women } \\
\hline Number (N) & \multicolumn{2}{|c|}{2752} & \multicolumn{2}{|c|}{3898} \\
\hline Age (year) & 49.9 & \pm 11.2 & 49.0 & \pm 11.3 \\
\hline $\mathrm{BMI}\left(\mathrm{kg} / \mathrm{m}^{2}\right)$ & 23.1 & \pm 3.0 & 22.9 & \pm 3.3 \\
\hline $\mathrm{SBP}(\mathrm{mmHg})$ & 136.2 & \pm 19.5 & 131.3 & \pm 19.9 \\
\hline $\mathrm{DBP}(\mathrm{mmHg})$ & 83.8 & \pm 11.7 & 79.4 & \pm 11.8 \\
\hline Total cholesterol (mg/dl) & 199.6 & \pm 36.6 & 205.5 & \pm 38.0 \\
\hline HDL cholesterol (mg/dl) & 50.4 & \pm 15.0 & 57.5 & \pm 14.9 \\
\hline Triglyceride (mg/dl) & 151.8 & \pm 108.8 & 119.1 & \pm 79.8 \\
\hline Blood glucose (mg/dl) & 102.0 & \pm 33.4 & 101.1 & \pm 28.9 \\
\hline \multicolumn{5}{|l|}{ Drinking } \\
\hline Non drinker & 921 & $33.5 \%$ & 3572 & $91.6 \%$ \\
\hline Ex-drinker & 141 & $5.1 \%$ & 39 & $1.0 \%$ \\
\hline Current drinker & 1690 & $61.4 \%$ & 287 & $7.4 \%$ \\
\hline \multicolumn{5}{|l|}{ Smoking } \\
\hline Never smoker & 556 & $20.2 \%$ & 3431 & $88.0 \%$ \\
\hline Ex-smoker & 601 & $21.8 \%$ & 94 & $2.4 \%$ \\
\hline Current smoker & 1595 & $58.0 \%$ & 373 & $9.6 \%$ \\
\hline Obesity & 689 & $25.1 \%$ & 912 & $23.4 \%$ \\
\hline High blood pressure & 1840 & $66.9 \%$ & 2119 & $54.4 \%$ \\
\hline High blood glucose & 578 & $21.0 \%$ & 829 & $21.3 \%$ \\
\hline Dyslipidemia & 1280 & $46.5 \%$ & 1094 & $28.1 \%$ \\
\hline
\end{tabular}

Values are number, \%, or mean \pm SD.

High blood pressure, $\mathrm{BP} \geq 130 / 85 \mathrm{mmHg}$ or on treatment of hypertension; high blood glucose, blood glucose $\geq 110 \mathrm{mg} / \mathrm{dl}$ or on treatment of diabetes; dyslipidemia as triglyceride $\geq 150 \mathrm{mg} / \mathrm{dl}$ or high density lipoprotein $<40 \mathrm{mg} / \mathrm{dl}$ or on treatment of dyslipidemia. $\mathrm{BMI}$, body mass index; SBP, systolic blood pressure; DBP, diastolic blood pressure; HDL, high density lipoprotein.

$9.6 \%$ in women. The prevalence of hypertension and obesity were $66.9 \%$ and $25.1 \%$ in men and $54.4 \%$ and $23.4 \%$ in women.

During 15 years of follow-up, 87 men and 61 women died due to CVD (37 men and 22 women died due to stroke and 30 men and 8 women died due to coronary heart disease). Table 2 shows HRs of CVD death for each component of metabolic risk factors including all factors in a model, simultaneously. It showed that current smoking, past-smoking, SBP and glucose were significant risk factors of CVD mortality. Table 3 shows adjusted HRs and PAFs for CVD deaths according to the combination of obesity and smoking status. Irrespective of obesity, smoking and CVD mortality in both men and women were positively related. HRs (95\% confidence interval [CI]) for non-obese smokers was 3.13 (1.33 to 7.36) in men and 4.32 (1.99 to 9.37) in women compared with
Table 2: Adjusted HR for 1 standard deviation increasing in the continuous variables and sex, smoking and drinking habits for mortality from cardiovascular diseases.

\begin{tabular}{lrrr}
\hline & $\begin{array}{l}\text { Adjusted hazard } \\
\text { ration }\end{array}$ \\
& & $95 \% \mathbf{C l})$ \\
\hline Current -smoker & 3.45 & $(2.12$ & $-5.60)$ \\
Past-smoker & 2.04 & $(1.11$ & $-3.75)$ \\
Body mass index (1 SD increasing) & 0.99 & $(0.83$ & $-1.18)$ \\
Systolic blood pressure (1 SD increasing) & 1.32 & $(1.13$ & $-1.54)$ \\
Triglyceride (1 SD increasing)* & 0.85 & $(0.69$ & $-1.04)$ \\
High density lipoprotein cholesterol (1 SD & 0.93 & $(0.76$ & $-1.11)$ \\
increasing) & & & \\
Glucose (1 SD increasing) & 1.10 & $(1.00$ & $-1.24)$ \\
Female & 1.00 & $(0.61$ & $-1.64)$ \\
\hline This Cox model also includes age, and drinking habit. & & \\
* The variable was tested after log-transferred. & & &
\end{tabular}

non-obese, non-smokers. Estimated numbers of excess CVD deaths (and PAF component) in the non-obese smokers and obese smokers were $32.0(36.8 \%)$, and 7.9 (9.1\%) in men and $6.9(11.3 \%)$ and $3.2(5.2 \%)$ in women. The sum of the estimated number of excess CVD deaths (PAF) due to smoking and/or obesity was 49.3 (56.9\%) in men and $15.3(25.1 \%)$ in women.

Table 4 shows adjusted HRs and PAF components due to combination of smoking status and metabolic syndrome. Compared to non-smokers without metabolic syndrome, adjusted HRs (95\% CI) for CVD deaths was higher in smokers with and without metabolic syndrome (HR 3.19 [1.13 to 9.03] and 3.47 [1.48 to 8.12] in men; 4.94 [1.52 to 16.09 ] and 3.63 [1.75 to 7.50 ] in women, respectively). PAFs for CVD mortality in smokers with and without metabolic syndrome were $7.1 \%$ and $40.9 \%$ in men and $3.9 \%$ and $11.9 \%$ in women, respectively. The sum of PAF components due to smoking and/or metabolic syndrome was $60.4 \%$ in men and $17.0 \%$ in women.

Table 5 shows adjusted HRs and PAF components due to the combination of smoking status and clustering of metabolic risk factors. Compared to non-smokers without metabolic risk factor clustering, adjusted HRs $(95 \%$ CI) for CVD death in smokers with and without metabolic risk factor clustering were 5.85 (1.40 to 24.38) and 4.17 (0.98 to 17.71 ) for men, and 5.86 (2.41 to 14.23 ) and 4.56 (1.62 to 12.87 ) for women, respectively. PAF components for CVD mortality in non-smokers with metabolic risk factors clustering, smokers without metabolic risk factors clustering and smokers with metabolic risk factors clustering were $2.8 \%, 20.1 \%$ and $34.3 \%$ for men, and $18.7 \%, 6.4 \%$ and $10.9 \%$ for women, respectively. 
Table 3: Hazard ratio and population attributable fraction for cardiovascular disease deaths according to the combination of smoking status and obesity*: NIPPON DATA90

\begin{tabular}{|c|c|c|c|c|c|c|c|c|c|c|}
\hline \multirow{2}{*}{$\overline{M e n}$} & & \multirow{2}{*}{$\begin{array}{l}\text { Number of } \\
\text { participants }\end{array}$} & \multirow{2}{*}{$\begin{array}{l}\text { Person-years of } \\
\text { follow-up }\end{array}$} & \multirow{2}{*}{$\begin{array}{c}\text { CVD } \\
\text { deaths (n) }\end{array}$} & \multirow{2}{*}{$\begin{array}{c}\text { CVD mortality rate } \\
\text { (per 1,000 person- } \\
\text { years) }\end{array}$} & \multicolumn{3}{|c|}{ Adjusted hazard ratio $(95 \% \mathrm{Cl}) \dagger$} & \multirow{2}{*}{$\begin{array}{l}\text { Estimated excess } \\
\text { CVD deaths (n) }\end{array}$} & \multirow{2}{*}{$\begin{array}{l}\text { PAF component for } \\
\text { CVD deaths }(\%)\end{array}$} \\
\hline & & & & & & & & & & \\
\hline \multirow[t]{2}{*}{ Non smoker } & Non-obese & 420 & 5938 & 6 & 1.01 & 1.00 & & & & \\
\hline & Obese & 136 & 1988 & 1 & 0.50 & 0.67 & $(0.08$ & $-5.53)$ & -- & -- \\
\hline \multirow[t]{2}{*}{ Past smoker } & Non-obese & 431 & 6116 & 16 & 2.62 & 1.93 & $(0.75$ & $-4.96)$ & 7.7 & 8.8 \\
\hline & Obese & 170 & 2414 & 5 & 2.07 & 1.52 & $(0.46$ & $-4.99)$ & 1.7 & 2.0 \\
\hline \multirow[t]{2}{*}{ Smoker } & Non-obese & 1212 & 16780 & 47 & 2.80 & 3.13 & $(1.33$ & $-7.36)$ & 32.0 & 36.8 \\
\hline & Obese & 383 & 5277 & 12 & 2.27 & 2.92 & $(1.09$ & $-7.82)$ & 7.9 & 9.1 \\
\hline \multicolumn{11}{|l|}{ Women } \\
\hline \multirow[t]{2}{*}{ Non smoker } & Non-obese & 2,638 & 37960 & 29 & 0.76 & 1.00 & & & & \\
\hline & Obese & 793 & 11256 & 17 & 1.51 & 1.34 & $(0.74$ & $-2.45)$ & 4.3 & 7.1 \\
\hline \multirow[t]{2}{*}{ Past smoker } & Non-obese & 66 & 843 & 1 & 1.19 & 1.43 & $(0.19$ & $-10.61)$ & 0.3 & 0.5 \\
\hline & Obese & 28 & 383 & 1 & 2.61 & 2.46 & $(0.33$ & $-18.09)$ & 0.6 & 1.0 \\
\hline \multirow[t]{2}{*}{ Smoker } & Non-obese & 282 & 3889 & 9 & 2.31 & 4.32 & $(1.99$ & $-9.37)$ & 6.9 & 11.3 \\
\hline & Obese & 91 & 1224 & 4 & 3.27 & 4.74 & $(1.66$ & $-13.58)$ & 3.2 & 5.2 \\
\hline
\end{tabular}

${ }^{*}$ Obesity was defined as body mass index $\geq 25 \mathrm{~kg} / \mathrm{m}^{2}$

tHazard ratios were adjusted for age and drinking.

CVD, cardiovascular diseases; PAF, population attributable fraction; $\mathrm{Cl}$, confidence interval. 
Table 4: Hazard ratio and population attributable fraction for cardiovascular disease deaths according to the combination of smoking status and metabolic syndrome: NIPPON DATA90.

\begin{tabular}{|c|c|c|c|c|c|c|c|}
\hline $\begin{array}{l}\text { Metabolic } \\
\text { syndrome* }\end{array}$ & $\begin{array}{l}\text { Number of } \\
\text { participants }\end{array}$ & $\begin{array}{l}\text { Person-years of } \\
\text { follow-up }\end{array}$ & CVD deaths (n) & $\begin{array}{c}\text { CVD mortality } \\
\text { rate (per } 1,000 \\
\text { person-years) }\end{array}$ & Adjusted hazard ratio $(95 \% \mathrm{Cl}) \dagger$ & $\begin{array}{l}\text { Estimated excess } \\
\text { CVD deaths ( } n \text { ) }\end{array}$ & $\begin{array}{l}\text { PAF component for } \\
\text { CVD deaths (\%) }\end{array}$ \\
\hline
\end{tabular}

\begin{tabular}{|c|c|c|c|c|c|c|c|c|c|c|}
\hline \multicolumn{11}{|l|}{ Men } \\
\hline \multirow[t]{2}{*}{ Non smoker } & - & 480 & 6817 & 6 & 0.88 & 1.00 & & & & \\
\hline & + & 76 & 1109 & 1 & 0.90 & 1.32 & $(0.16$ & $-10.97)$ & 0.2 & 0.3 \\
\hline \multirow[t]{2}{*}{ Past smoker } & - & 494 & 7036 & 18 & 2.56 & 2.13 & $(0.84$ & $-5.39)$ & 9.5 & 11.0 \\
\hline & + & 107 & 1494 & 3 & 2.01 & 1.49 & $(0.37$ & $-6.01)$ & 1.0 & 1.1 \\
\hline \multirow[t]{2}{*}{ Smoker } & - & 1343 & 18620 & 50 & 2.69 & 3.47 & $(1.48$ & $-8.12)$ & 35.6 & 40.9 \\
\hline & + & 252 & 3437 & 9 & 2.62 & 3.19 & $(1.13$ & $-9.03)$ & 6.2 & 7.1 \\
\hline \multicolumn{11}{|l|}{ Women } \\
\hline \multirow[t]{2}{*}{ Non smoker } & - & 3,034 & 43585 & 38 & 0.87 & 1.00 & & & & \\
\hline & + & 397 & 5631 & 8 & 1.42 & 0.83 & $(0.38$ & $-1.78)$ & -- & -- \\
\hline \multirow[t]{2}{*}{ Past smoker } & - & 81 & 1042 & 1 & 0.96 & 1.06 & $(0.15$ & $-7.81)$ & 0.05 & 0.1 \\
\hline & + & 13 & 184 & 1 & 5.45 & 2.98 & $(0.41$ & $-21.79)$ & 0.6 & 1.1 \\
\hline \multirow[t]{2}{*}{ Smoker } & - & 336 & 4627 & 10 & 2.16 & 3.63 & $(1.75$ & $-7.50)$ & 7.2 & 11.9 \\
\hline & + & 37 & 486 & 3 & 6.17 & 4.94 & (1.52 & $-16.09)$ & 2.4 & 3.9 \\
\hline
\end{tabular}

*Metabolic syndrome were defined as follows: obesity (body mass index $\geq 25 \mathrm{~kg} / \mathrm{m}^{2}$ ) plus any two of the following three factors: high blood pressure as blood pressure $\geq 130 / 85 \mathrm{mmHg}$ or on

treatment of hypertension, high blood glucose as blood glucose $\geq 110 \mathrm{mg} / \mathrm{dl}$ or on treatment of diabetes, dyslipidemia as triglyceride $\geq 150 \mathrm{mg} / \mathrm{dl}$ or high density lipoprotein cholesterol $<40 \mathrm{mg} /$ dl or on treatment of dyslipidemia.

tHazard ratios were adjusted for age and drinking.

CVD, cardiovascular diseases; PAF, population attributable fraction; $\mathrm{Cl}$, confidence interval. 
Table 5: Hazard ratio and population attributable fraction for cardiovascular disease deaths according to the combination of smoking status and clustering of metabolic risk factors: NIPPON DATA90.

\begin{tabular}{|c|c|c|c|c|c|c|c|c|c|c|}
\hline \multirow[b]{2}{*}{ Men } & \multirow[t]{2}{*}{$\begin{array}{l}\text { Clustering of } \\
\text { metabolic risk } \\
\text { factors* }\end{array}$} & \multirow[t]{2}{*}{$\begin{array}{l}\text { Number of } \\
\text { participants }\end{array}$} & \multirow[t]{2}{*}{$\begin{array}{l}\text { Person-years of } \\
\text { follow-up }\end{array}$} & \multirow[t]{2}{*}{$\begin{array}{c}\text { CVD } \\
\text { deaths }(n)\end{array}$} & \multirow[t]{2}{*}{$\begin{array}{l}\text { CVD mortality } \\
\text { rate (per } 1,000 \\
\text { person-years) }\end{array}$} & \multicolumn{3}{|c|}{ Adjusted hazard ratio $(95 \% \mathrm{Cl}) \dagger$} & \multirow[t]{2}{*}{$\begin{array}{c}\text { Estimated } \\
\text { excess CVD } \\
\text { deaths (n) }\end{array}$} & \multirow[t]{2}{*}{$\begin{array}{l}\text { PAF component for } \\
\text { CVD deaths (\%) }\end{array}$} \\
\hline & & & & & & & & & & \\
\hline \multirow[t]{2}{*}{ Non smoker } & 0 or 1 & 281 & 4002 & 2 & 0.50 & 1.00 & & & & \\
\hline & $2 \leq$ & 275 & 3924 & 5 & 1.27 & 1.94 & $(0.38$ & $-10.00)$ & 2.4 & 2.8 \\
\hline \multirow[t]{2}{*}{ Past smoker } & 0 or 1 & 282 & 4084 & 7 & 1.71 & 2.41 & $(0.50$ & $-11.65)$ & 4.1 & 4.7 \\
\hline & $2 \leq$ & 319 & 4446 & 14 & 3.15 & 3.37 & $(0.76$ & $-14.96)$ & 9.8 & 11.3 \\
\hline \multirow[t]{2}{*}{ Smoker } & 0 or 1 & 819 & 11465 & 23 & 2.01 & 4.17 & $(0.98$ & $-17.71)$ & 17.5 & 20.1 \\
\hline & $2 \leq$ & 776 & 10592 & 36 & 3.40 & 5.85 & $(1.40$ & $-24.38)$ & 29.8 & 34.3 \\
\hline \multicolumn{11}{|l|}{ Women } \\
\hline \multirow[t]{2}{*}{ Non smoker } & 0 or 1 & 2,117 & 30554 & 14 & 0.46 & 1.00 & & & & \\
\hline & $2 \leq$ & 1314 & 18661 & 32 & 1.71 & 1.55 & $(0.82$ & $-2.95)$ & 11.4 & 18.7 \\
\hline \multirow[t]{2}{*}{ Past smoker } & 0 or 1 & 54 & 698 & 0 & -- & & & -- & -- & -- \\
\hline & $2 \leq$ & 40 & 527 & 2 & 3.79 & 3.08 & $(0.69$ & $-13.81)$ & 1.4 & 2.2 \\
\hline \multirow[t]{2}{*}{ Smoker } & 0 or 1 & 222 & 3098 & 5 & 1.61 & 4.56 & $(1.62$ & $-12.87)$ & 3.9 & 6.4 \\
\hline & $2 \leq$ & 151 & 2016 & 8 & 3.97 & 5.86 & $(2.41$ & $-14.23)$ & 6.6 & 10.9 \\
\hline
\end{tabular}

* Metabolic risk factors were any of the following four factors: obesity (body mass index $\geq 25 \mathrm{~kg} / \mathrm{m}^{2}$ ), high blood pressure as blood pressure $\geq 130 / 85 \mathrm{mmHg}$ or on treatment of hypertension, high blood glucose as blood glucose $\geq 110 \mathrm{mg} / \mathrm{dl}$ or on treatment of diabetes, dyslipidemia as triglyceride $\geq 150 \mathrm{mg} / \mathrm{dl}$ or high density lipoprotein cholesterol $<40 \mathrm{mg} / \mathrm{dl}$ or on treatment of dyslipidemia. tHazard ratios were adjusted for age and drinking.

CVD, cardiovascular diseases; PAF, population attributable fraction; $\mathrm{Cl}$, confidence interval. 


\section{Discussion}

The present report of a representative Japanese cohort showed that the majority of excess CVD deaths were observed in smokers without metabolic syndrome. The PAF component of CVD deaths in smokers without metabolic syndrome were 5 times higher than those in participants with metabolic syndrome in men (40.9\% vs. $8.5 \%)$. The HR of CVD deaths in smokers without metabolic syndrome were also higher than non-smokers without metabolic syndrome, and it was similar to the HR in smokers with metabolic syndrome (3.47 vs. 3.19).

In Asian countries including Japan, there has been a rise in metabolic syndrome [7,25]. In these areas, prevalence of smoking has been higher than that in Western countries and smoking rates has been still increasing in younger women [14]. Previous studies have reported that obesity and smoking are risk factors for CVD $[5,6,10,11]$. The association of clustering of metabolic risk factors, including hyperglycemia, dyslipidemia, and hypertension, with CVD risk has also been widely reported $[1,4,17,18]$. Furthermore, a previous study from Japan reported that the effect of risk factor accumulation on CVD incidence was more evident among smokers than non smokers [17]. However, these previous reports did not show the attribution of the combination of smoking and metabolic syndrome (or obesity) to CVD events. To our knowledge, this is the first report showing that the majority of excess CVD deaths occurred in smokers without metabolic syndrome in a Asian population. A strength of our report is that the study was conducted in a 15-year cohort of nationwide representative Japanese samples.

In Japan, new health checkups and healthcare advice focusing on the metabolic syndrome to prevent CVD began in April 2008 through health insurance providers [7]. Our results support the necessity of intervention for people with metabolic syndrome because these people appear to be at higher CVD risk; however, PAF component in men and in women with metabolic syndrome were only $8.5 \%$ and $5.0 \%$, respectively. On the other hand, the present study indicated that PAFs among smokers without metabolic syndrome were $40.9 \%$ in men and $11.9 \%$ in women; who are not the target population of the new health educational program in Japan. Moreover, not only PAF but also HR of smokers without metabolic syndrome was substantially higher. Thus the program might overlook a large population at an increased risk of CVD. Activities of smoking cessation for non-obese people would be still important for the prevention of CVD in Japan.

In the present study, we examined the association between each component of metabolic risk factors and CVD death. We conformed that current and past smok- ing, SBP and glucose were significant risk factors of CVD mortality in our study participants. Several previous reports revealed that clustering of metabolic risk factors increases CVD risk, irrespective of the presence of obesity $[17,18]$. When obesity was dealt with one of metabolic risk factors (not an essential factor) in the present study (Table 5), the PAF in smokers with metabolic risk factor clustering got larger in men (34.3\%). However, even for smokers without metabolic risk factors clustering in the present study, PAF was $20.1 \%$ in men. This finding indicated that even if obesity is not essential for the diagnostic criteria of metabolic syndrome like the National Cholesterol Education Program (NCEP) [26], an intervention for smokers without clustering of metabolic risk factors would be also important for the prevention of CVD.

This study has several limitations. First, we used nonfasting blood samples and thus we might have misclassified several individuals with diabetes and dyslipidemia. Second, we used body mass index $\geq 25 \mathrm{~kg} / \mathrm{m}^{2}$ to define obesity and thus we might have misclassified individuals with abdominal obesity with higher waist circumference. However, this limitation would be ignorable because the correlation between BMI and waist circumstance is usually high enough. The cut-off point of body mass index for Japanese [21] is different from that for Asia-Pacific Region in the WHO definition (body mass index $\geq 23 \mathrm{~kg} /$ $\mathrm{m}^{2}$ ) [27], which may underestimate the PAF in Asian people. Third, we did not adjust for socioeconomic status in this study. However, all Japanese are covered by the national health insurance program and socioeconomic status would not limit access to treatment in Japan. Fourth, in this study, we used information on smoking habit from self-reported smoking history; this may cause recall and information biases. Fifth, the numbers of participants or CVD events were not enough to analyze according to the number of cigarettes per day; therefore, we did not consider the intensity of smoking in this paper.

\section{Conclusions}

In conclusion, this long-term cohort study of representative Japanese samples indicated that CVD mortality in smokers without metabolic syndrome or without obesity was substantially high and a large proportion of excess deaths were observed in these groups. These findings suggest that intervention targeting on smokers, irrespective of the presence of metabolic syndrome (or obesity), is still important for the prevention of CVD death in relatively lean Japanese population with high smoking rate. This could apply to other Asian populations with high smoking rate but with lower prevalence of obesity compared with Western populations. 


\section{Competing interests}

The authors declare that they have no competing interests.

\section{Authors' contributions}

All authors contributed to the concept, design, analysis, interpretation of data, and preparation of the manuscript. All authors read and approved the final manuscript.

\section{Acknowledgements}

The authors thank all public health centers that cooperated with our study. List of the NIPPON DATA90 Research Group

Chairperson: Hirotsugu Ueshima (Department of Health Science, Shiga University of Medical Science, Otsu, Shiga).

Research members: Akira Okayama (The First Institute for Health Promotion and Health Care, Japan Anti-Tuberculosis Association, Tokyo), Kazunori Kodama and Fumiyoshi Kasagi (Radiation Effects Research Foundation, Hiroshima), Shigeyuki Saitoh (Department of 2nd Internal Medicine, Sapporo Medical University, Sapporo, Hokkaido), Kiyomi Sakata (Department of Hygiene and Preventive Medicine, Iwate Medical University, Morioka, Iwate), Yoshikazu Nakamura (Department of Public Health, Jichi Medical University, Shimotsuke, Tochigi), Yoshikuni Kita (Department of Health Science, Shiga University of Medical Science, Otsu, Shiga), Tomonori Okamura (Department of Preventive Cardiology, National Cardiovascular Center, Suita, Osaka), Koji Tamakoshi (Department of Public Health and Health Information Dynamics, Nagoya University Graduate School of Medicine, Nagoya, Aichi), Yasuyuki Nakamura (Cardiovascular Epidemiology, Kyoto Women's University, Kyoto), Yutaka Kiyohara (Department of Environmental Medicine, Kyushu University, Fukuoka), Yasuhiro Matsumura (Faculty of Healthcare, Kiryu University, Midori City, Gunma), Katsushi Yoshita (Project for the Naitonal Health and Nutrition Survey, National Institute of Health and Nutrition, Tokyo), Hideaki Nakagawa (Department of Epidemiology and Public Health, Kanazawa Medical University, Ishikawa), Takehito Hayakawa (Department of Hygiene and Preventive Medicine, Fukushima Medical University, Fukushima), Katsuyuki Miura (Department of Health Science, Shiga University of Medical Science, Otsu, Shiga), Toshiyuki Ojima (Department of Community Health and Preventive Medicine, Hamamatsu University School of Medicine, Hamamatsu, Shizuoka), Nagako Okuda (Department of Health Science, Shiga University of Medical Science, Otsu, Shiga), Atsushi Hozawa (Division of Epidemiology, Department of Public Health and Forensic Medicine, Tohoku University School of Medicine, Sendai, Miyagi). Role of Sponsor: The sponsors did not participate in the design or conduct of the study; the collection; management, analysis, and interpretation of the study; or the preparation, review, or approval of the manuscript. Funding: This study was supported by the grant-in-aid of the Ministry of Health and Welfare under the auspices of Japanese Association for Cerebro-cardiovascular Disease Control, the Research Grant for Cardiovascular Diseases (7A-2) from the Ministry of Health, Labour and Welfare and a Health and Labour Sciences Research Grant, Japan (Comprehensive Research on Aging and Health: H11-chouju-046, H14-chouju-003, H17-chouju-012 and H19-chouju-014).

\section{Author Details}

'Department of Health Science, Shiga University of Medical Science, Seta Tsukinowa-cho, Otsu, Shiga 520-2192, Japan, 2Department of Public Health, Yamagata University School of Medicine, lida Nishi 2-2-1, Yamagata, Yamagata, 990-9585, Japan, ${ }^{3}$ Department of Preventive Cardiology, National Cardiovascular Center, Fujishirodai 5-7-1, Suita, Osaka, 565-8565, Japan, ${ }^{4}$ The Cardiovascular Epidemiology, Kyoto Women's University, Imakumanokitahiyoshi-cho35, Kyoto, Kyoto, 605-8501, Japan, ${ }^{5}$ Department of Hygiene and Preventive Medicine, Fukushima Medical University, Hikarigaoka1, Fukushima, Fukushima, 960-1295, Japan and ${ }^{\top}$ The First Institute for Health Promotion and Health Care, Japanese Anti-Tuberculosis Association, Misakicho1-3-12, Chiyoda, Tokyo, 101-061, Japan

Received: 29 September 2009 Accepted: 3 June 2010 Published: 3 June 2010

\section{References}

1. Criqui MH, Barrett-Connor E, Holdbrook MJ, Austin M, Turner JD: Clustering of cardiovascular disease risk factors. Prev Med 1980, 9:525-33.
2. Reaven GM: Banting lecture 1988. Role of insulin resistance in human disease. Diabetes 1988, 37:1595-607.

3. Kaplan NM: The deadly quartet. Upper-body obesity, glucose intolerance, hypertriglyceridemia, and hypertension. Arch Intern Med 1989, 149:1514-20.

4. DeFronzo RA, Ferrannini E: Insulin resistance. A multifaceted syndrome responsible for NIDDM, obesity, hypertension, dyslipidemia, and atherosclerotic cardiovascular disease. Diabetes Care 1991, 14:173-94.

5. World Health Organization: Obesity: preventing and managing the global epidemic. Report of a WHO consultation. Geneva, Switzerland: World Health Organization; 2004

6. Melanson KJ, McInnis KJ, Rippe JM, Blackburn G, Wilson PF: Obesity and cardiovascular disease risk: research update. Cardiol Rev 2001, 9:202-7.

7. Annual Report on Health Labour Welfare. Tokyo Japan Ministry of Health Labour and Welfare; 2007. (in Japanese)

8. Lakier JB: Smoking and cardiovascular disease. Am J Med 1992, 93:8S-12S.

9. Ueshima H, Choudhury SR, Okayama A, Hayakawa T, Kita Y, Kadowaki T, Okamura T, Minowa M, limura O: Cigarette smoking as a risk factor for stroke death in Japan: NIPPON DATA80. Stroke 2004, 35:1836-41.

10. Higa M, Davanipour Z: Smoking and stroke. Neuroepidemiology 1991, 10:211-22.

11. Seltzer CC: Framingham study data and "established wisdom" about cigarette smoking and coronary heart disease. J Clin Epidemiol 1989, 42:743-50.

12. Murakami Y, Ueshima H, Okamura T, Kadowaki T, Hozawa A, Kita Y, Hayakawa T, Okayama A: Life expectancy among Japanese of different smoking status in Japan: NIPPON DATA80. J Epidemiol 2007, 17:31-7.

13. Ueshima H, Sekikawa A, Miura K, Turin TC, Takashima N, Kita Y, Watanabe M, Kadota A, Okuda N, Kadowaki T, Nakamura Y, Okamura T: Cardiovascular Disease and Risk Factors in Asian: A Selected Review. Circulation 2008, 118:2702-2709.

14. Brundtland GH: The Tobacco Atlas. Geneva Switzerland the World Health Organization; 2002.

15. Health and Welfare Statistics Association: Journal of Health and Welfare Statistics. Tokyo Japan Health and Welfare Statistics Association. 2007. (in Japanese)

16. Martiniuk AL, Lee CM, Lam TH, Huxley R, Suh I, Jamrozik K, Gu DF, Woodward M, Asia Pacific Cohort Studies Collaboration: The fraction of ischaemic heart disease and stroke attributable to smoking in the WHO Western Pacific and South-East Asian regions. Tob Control 2006, 15:181-8.

17. Iso H, Sato S, Kitamura A, Imano H, Kiyama M, Yamagishi K, Cui R, Tanigawa $T$, Shimamoto T: Metabolic syndrome and the risk of ischemic heart disease and stroke among Japanese men and women. Stroke 2007, 38:1744-51.

18. Kadota A, Hozawa A, Okamura T, Kadowaki T, Nakmaura K, Murakami Y, Hayakawa T, Kita Y, Okayama A, Nakamura Y, Kashiwagi A, Ueshima H: Relationship between metabolic risk factor clustering and cardiovascular mortality stratified by high blood glucose and obesity: NIPPON DATA90, 1990-2000. Diabetes Care 2007, 30:1533-8.

19. Okamura T, Hayakawa T, Kadowaki T, Kita Y, Okayama A, Ueshima H, NIPPON DATA90 Research Group: The inverse relationship between serum high-density lipoprotein cholesterol level and all-cause mortality in a 9.6-year follow-up study in the Japanese general population. Atherosclerosis 2006, 184:143-50.

20. Nakamura M, Sato S, Shimamoto T: Improvement in Japanese clinical laboratory measurements of total cholesterol and HDL-cholesterol by the US Cholesterol Reference Method Laboratory Network. J Atheroscler Thromb 2003, 10:145-153.

21. Examination Committee of Criteria for 'Obesity Disease' in Japan; Japan Society for the Study of Obesity: New criteria for 'obesity disease' in Japan. Circ J 2002, 66:987-92.

22. Committee to Evaluate Diagnostic Standards for Metabolic Syndrome: Definition and the diagnostic standard for metabolic syndrome-Committee to Evaluate Diagnostic Standards for Metabolic Syndrome. Nippon Naika Gakkai Zasshi 2005, 94:794-809. (in Japanese)

23. Rockhill B, Newman B, Weinberg C: Use and misuse of population attributable fractions. Am J Public Health 1998, 88:15-9.

24. Hozawa A, Okamura T, Murakami Y, Kadowaki T, Nakamura K, Hayakawa T, Kita Y, Nakamura Y, Abbott RD, Okayama A, Ueshima H: Joint impact of smoking and hypertension on cardiovascular disease and all-cause 
mortality in Japan: NIPPON DATA80, a 19-year follow-up. Hypertens Res 2007, 30:1169-75.

25. World Health Organization: World Health Statistics 2007. Geneva, Switzerland: World Health Organization; 2007.

26. Executive summary of the Third Report of the National Cholesterol

Education Program (NCEP): Expert Panel on Detection, Evaluation, and Treatment of High Blood Cholesterol in Adults (Adult Treatment Panel III). JAMA 2001, 285:2486-2497.

27. Choo V: WHO reassesses appropriate body-mass index for Asian populations. Lancet 2002, 360:235.

\section{Pre-publication history}

The pre-publication history for this paper can be accessed here: http://www.biomedcentral.com/1471-2458/10/306/prepub

\section{doi: $10.1186 / 1471-2458-10-306$}

Cite this article as: Takashima et al., Population Attributable Fraction of Smoking and Metabolic Syndrome on Cardiovascular Disease Mortality in Japan: a 15-Year Follow Up of NIPPON DATA90 BMC Public Health 2010, 10:306

Submit your next manuscript to BioMed Centra and take full advantage of:

- Convenient online submission

- Thorough peer review

- No space constraints or color figure charges

- Immediate publication on acceptance

- Inclusion in PubMed, CAS, Scopus and Google Scholar

- Research which is freely available for redistribution 